Ege Tıp Dergisi / Ege Journal of Medicine 2018;57(3):163-166

\title{
Diz osteoartritli hastalarda ortalama trombosit hacminin hastalık parametreleri ile ilişkisi
}

The association between mean platelet volume and disease parameters in knee osteoarthritis

\author{
Neslihan Gökçen İlke Coşkun Benlidayı Sibel Başaran \\ Çukurova Üniversitesi Tıp Fakültesi, Fiziksel Tıp ve Rehabilitasyon Anabilim Dalı, Adana, Türkiye
}

Öz

Amaç: Ortalama trombosit hacmi (mean platelet volume-MPV), platelet büyüklüğünü ve aktivitesi gösteren bir belirteçtir. MPV'nin, proinflamatuvar ve protrombik durumları yansıttığı bilinmektedir. Bazı çalışmalarda, MPV seviyelerinin, sinovitli hastalarda inflamasyon ve eritrosit sedimentasyon hızı (ESH) ile negatif ilişkili olduğu saptanmıştır. Bu bilgiler doğrultusunda, çalışmamızda dizde osteoartrit (OA) bulunan hastalarda MPV düzeyinin, radyolojik evre, klinik durum ve inflamatuvar belirteçler ile ilişkisinin araştırılması planlanmıştır.

Gereç ve Yöntem: Çalışmamıza Ocak 2016-Mart 2016 tarihleri arasında polikliniğimize başvuran ve diz OA tanısı ile takip edilen 160 hasta dahil edildi. Hastaların MPV, ESH ve C-reaktif protein (CRP) değerleri kaydedildi. Hastaların ağrı şiddetini ölçmek için vizüel anolog skala (VAS), fonksiyonel durumlarını değerlendirmek için Western Ontario ve McMaster Üniversiteleri Osteoartrit İndeksi (WOMAC) formu kullanıldı. Anteroposterior diz radyografilerinde Kellgren-Lawrence $(\mathrm{KL})$ yöntemine göre radyolojik evreleme yapıldı.

Bulgular: MPV değeri ile ESH, CRP, total WOMAC skoru ve vizüel anolog skala (VAS) arasında korelasyon saptanmazken, MPV ile platelet sayımı negatif korele idi ( $r=-0.374)$. MPV seviyeleri, KL gruplarına (KL 1-4) göre analiz edildiğinde, gruplar arasında fark gözlenmedi $(p=0.090)$. Hastalar hafif $(K L 1-2)$ ve orta-ileri evre $(K L 3-4)$ OA olarak değerlendirildiğinde, gruplar arasında MPV seviyeleri açısından anlamlı fark saptanmadı $(p=0.066)$.

Sonuç: Diz OA'ı hastalarda, MPV seviyesi; radyolojik evreden bağımsız olup, klinik durum, ESH ve CRP düzeyleri ile de ilişkili bulunmamıştır. MPV'nin osteoartrit aktivitesindeki olası rolünün değerlendirilebilmesi için daha kapsamlı çalışmalara ihtiyaç vardır.

Anahtar Sözcükler: C-reaktif protein, eritrosit sedimentasyon hızı, osteoartrit, ortalama trombosit hacmi.

\section{Abstract}

Aim: Mean platelet volume (MPV) is a marker that indicates platelet volume and activation as well as inflammatory conditions such as osteoarthritis with synovitis, rheumatoid arthritis and ankylosing spondylitis. The aim of the present study was to investigate the relationship between MPV level and the variables of physical examination, laboratory tests, and radiographic measurements in patients with knee osteoarthritis (OA).

Material and Methods: In this cross-sectional study, 160 patients with knee OA admitted to the Physical Medicine and Rehabilitation Department between January 2013 and November 2015 were included. MPV levels, erythrocyte sedimentation rate (ESR) and C-reactive protein (CRP) of patients were obtained from electronic database of the hospital. Western Ontario and McMaster Universities Osteoarthritis Index (WOMAC) was used to evaluate patients' symptoms and disability. Also, patients' pain was scored by visual analog scale (VAS). Knee $O A$ was graded according to the Kellgren-Lawrence $(K L)$ classification system on plain anteroposterior knee radiographs.

\footnotetext{
Yazışma Adresi: Neslihan Gökçen

Çukurova Üniversitesi Tıp Fakültesi, Fiziksel Tıp ve

Rehabilitasyon Anabilim Dalı, Adana, Türkiye

Makalenin Geliş Tarihi:24.07.2017 Kabul Tarihi:12.09.2017
} 
Results: No correlation was found between MPV and the parameters including ESR, CRP, visual analog scale score and WOMAC score. MPV was negatively correlated with platelet count $(r=-0.374)$. When MPV level was analyzed with regard to the $K L$ grades, no difference was found among groups $(p=0.090)$. When patients were divided into two groups as mild OA (KL grade 1-2) and moderate-severe OA (KL grade 3-4), there was no difference between the groups in terms of MPV level ( $p=0.066)$.

Conclusion: No association was detected between MPV level and the parameters. Further studies are needed to evaluate the role of MPV level in disease activity among patients with knee osteoarthritis.

Keywords: C-reactive protein, erythrocyte sedimentation rate, osteoarthritis, mean platelet volüme.

\section{Giriş}

Ortalama trombosit hacmi (MPV), platelet büyüklüğünü ve aktivitesi gösteren bir belirteçtir. MPV'nin, proinflamatuvar ve protrombik durumları yansıttığı bilinmektedir (1-3). İnflamasyon, kemik iliğinde platelet üretimini ve salınımını artıran nedenlerden biridir ve çeşitli inflamatuvar hastalıklarda yapılan çalışmalarda hem artmış, hem de azalmış MPV değerleri gösterilmiştir (1,4-7). Bu çelişkili sonuçların nedeni olarak; kemik iliğinde üretimin artması ile salınan genç plateletlerin MPV'yi arttırdığını söyleyen yayınlarla birlikte $(2,7)$, artan üretimin küçük platelet salınımına neden olarak MPV'yi azalttığını iddia eden yayınlar gösterilebilmektedir (8). Ankilozan spondilit, romatoid artrit, sistemik lupus eritematozus, inflamatuvar barsak hastalığı ve Behçet hastalığı gibi birçok romatizmal hastalığın yanı sıra sinoviti olan osteoartrit (OA) hastalarında da MPV ile inflamasyon, hastalık aktivitesi ve klinik arasındaki ilişki araştıııııştır (1,4,9-11). MPV seviyelerinin, sinovitli hastalarda inflamasyon ve Eritrosit sedimentasyon hızı (ESH) ile negatif ilişkili olduğu saptanmıştır $(1,4,5)$. MPV'nin inflamasyonun bir belirteci ve hastalık aktivitesinin bir göstergesi olarak kullanılabileceği düşünülmüştür $(1,11)$. Ancak, klinik olarak sinoviti olmayan OA hastalarında MPV değerlerinin incelendiği literatür verisi sınırlıdır. $\mathrm{Bu}$ bilgiler doğrultusunda, çalışmamızda diz OA'ı hastalarda MPV düzeyinin, hastalık radyolojik evresi, klinik durum ve inflamatuvar belirteçler ile ilişkisinin araştırı Iması planlanmaktadır.

\section{Gereç ve Yöntem}

Hasta popülasyonu

Çalışmaya Ocak 2016-Mart 2016 tarihleri arasında Çukurova Üniversitesi Tıp Fakültesi Fiziksel Tıp ve Rehabilitasyon polikliniğine başvuran ve diz OA tanısı ile takip edilen 160 hasta dahil edildi. 40-70 yaş arası ve American College of Rheumatology klinik ve radyolojik tanı kriterlerine göre primer OA tanısı olan hastalar çalışmaya dahil edilirken, alt ekstremite operasyon veya travma öyküsü, malignite öyküsü, hemipleji veya parapleji gibi nörolojik hastalıkları olan ve romatoid artrit, ankilozan spondilit gibi inflamatuvar hastalıkları olan hastalar çalışmaya dahil edilmedi.
Çalışma için Çukurova Üniversitesi Tıp Fakültesi Etik Kurulu'ndan onay ve hastalardan çalışmaya gönüllü olarak katıldıklarını gösteren bilgilendirilmiş olur formu alındı.

\section{Değerlendirme}

Çalışmaya dahil edilen hastaların standart bir veri formuna göre demografik verileri, antropometrik ölçümleri, şikayetleri ve fizik muayene bulguları kaydedildi. Antropometrik ölçümleri (boy, kilo) alınan hastaların vücut kütle indeksleri (VKI) hesaplandı. Hastaların ağrı şiddetini ölçmek için vizüel anolog skala (VAS) kullanıldı, 0 (ağrı olmaması) ile 100 (dayanılmaz ağrı) arasında derecelendirildi. Hastaların fonksiyonel durumlarını değerlendirmek için Western Ontario ve McMaster Üniversiteleri Osteoartrit İndeksi (WOMAC) formu kullanıldı. Bu çalışmada WOMAC 3.1 normalize edilmiş versiyonu kullanıldı (12). Eritrosit sedimentasyon hızı (ESH), C-reaktif protein (CRP) değerleri ve tam kan sayımı sonuçlarından MPV değerleri kaydedildi. Tam kan sayımı, elektriksel impedans fotometri (Sysmex XN-1000); ESH, kapiller fotometri (ALIFAX test 1); CRP ise immünofelometrik (IMMAGE-800) yöntemi ile ölçüldü. Tam kan sayımı hastanemiz laboratuvar politikası ve prosedürü gereği bir saat içinde ölçüme alındı. Hastaların mevcut anteroposterior diz radyografilerinde KellgrenLawrence $(\mathrm{KL})$ yöntemine göre 0-4 arasında radyolojik evreleme yapıldı. $\mathrm{KL}$ yöntemine göre normal eklem Evre 0; şüpheli osteofit, normal eklem aralığı veya şüpheli daralma Evre 1; belirgin osteofit, eklem aralığında minimal daralma Evre 2; orta derece osteofit, eklem aralığında orta derecede daralma, skleroz Evre 3 ve büyük osteofit, eklem aralığında ciddi daralma, ciddi subkondral skleroz Evre 4 olarak evrelendi $(1,13)$.

Istatistiksel analiz

İstatistiksel analiz SPSS ${ }^{\circledR}$ Statistics versiyon 20.0 kullanılarak gerçekleştirildi. Tanımlayıcı istatistik yöntemleri kullanılarak demografik verilerin analizi yapıldı. Verilerin normal dağııma uygunluğu normalite testi ile değerlendirildi. Normal dağılıma uymayan değişkenler için yapılan tanımlayıcı istatistik analiz sonrası, ortanca (minimum-maksimum) değerleri 
belirlendi. Korelasyon analizine alınan değişkenler normal dağılıma uymadığı için, MPV değerlerinin klinik ve laboratuvar bulguları ile ilişkisi Spearman korelasyon analizi kullanılarak gerçekleştirildi. Normal dağılım göstermeyen sürekli değişkenlerin analizinde Mann Whitney $U$ veya Kruskall Wallis testi kullanıldı. p değerinin 0.05 'ten küçük olduğu durumlar istatistiksel olarak anlamlı kabul edildi. Korelasyon kat sayısı (r) 00.24 arası ilişki yok veya çok zayıf ilişki, 0.25-0.49 arası zayıf-orta derece, 0.50-0.74 arası iyi derece, 0.75-1.00 arası ise çok iyi derece ilişki olarak yorumlandı (14).

\section{Bulgular}

Çalışmaya 136'sı kadın (\%85), 24'ü erkek (\%15) toplam 160 diz OA hastası dahil edildi. Hastaların yaş ortalaması $57.2 \pm 7.6 \mathrm{yıl}$, vücut kütle indeksi ortalaması $34.1 \pm 6.0 \mathrm{~kg} / \mathrm{m}^{2}$ idi. MPV ortanca (min-maks) değeri 8.6 $\mathrm{fL}$ (6.3-13.5) idi. Hastaların 127'sinde (\%79.4) CRP $\leq 0.8$ iken, 33'ünde (\%20.6) CRP >0.8 idi.

MPV değeri ile ESH, CRP, total WOMAC skoru ve VAS arasında korelasyon saptanmazken (sırasıyla, $r=-$ $0.108,-0.016,-0.009,-0.018)$, platelet sayımı ile korele idi $(r=-0.374)$ (Tablo-1). Platelet sayımı ayrıca ESH ve CRP ile de korele bulundu. MPV değerleri ile ESH, CRP, total WOMAC skoru ve VAS arasında istatistiksel olarak anlamlı bir fark bulunmadı. $\mathrm{KL}$ evrelemesine göre (1-4) gruplar arası MPV değerleri sırası ile $8.7 \mathrm{fL}$ (7.0-12.5), 8.6 fL (7.3-13.5), 8.6 fL (6.3-11.8), $7.7 \mathrm{fL}$ (6.9-12.1) idi (Şekil-1). Tüm KL grupları arasında karşılaştırmalı analiz yapıldığında MPV seviyelerinin gruplar arasında fark gözlenmedi $(p=0.090)$. Hastalar erken (KL 1-2) ve ileri evre (KL 3-4) OA olarak değerlendirildiğinde, gruplar arasında MPV seviyeleri açısından anlamlı fark saptanmadı $(p=0.066)$.

Tablo-1. MPV ile Klinik ve Laboratuvar Değişkenleri Arasındaki Korelasyon.

\begin{tabular}{|c|c|c|c|c|c|c|}
\hline Değişkenler & MPV & WOMAC & VAS & ESH & CRP & $\begin{array}{l}\text { Platelet } \\
\text { sayım }\end{array}$ \\
\hline MPV & 1 & -0.009 & -0.018 & $\begin{array}{l}0.10 \\
8\end{array}$ & $\begin{array}{l}0.01 \\
6\end{array}$ & $-0.374^{\S}$ \\
\hline WOMAC & & 1 & $0.886^{\S}$ & 0.295 & 0.216 & 0.093 \\
\hline VAS & & & 1 & 0.257 & 0.248 & 0.042 \\
\hline ESH & & & & 1 & $0_{\S}^{0.460}$ & $0.227^{\pi}$ \\
\hline CRP & & & & & 1 & $0.221^{\pi}$ \\
\hline $\begin{array}{l}\text { Platelet } \\
\text { sayımı }\end{array}$ & & & & & & 1 \\
\hline
\end{tabular}

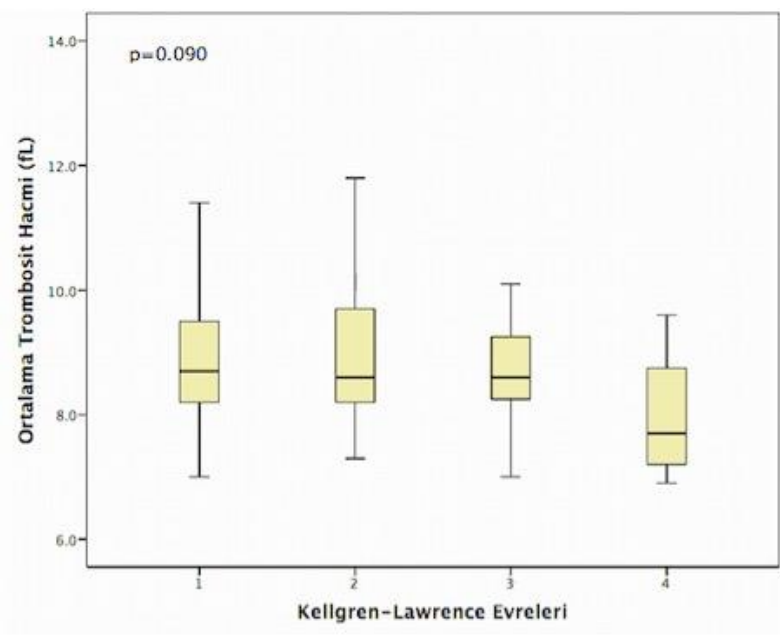

Şekil-1. Kellgren-Lawrence evrelemesine göre gruplar arası ortalama trombosit hacmi değerleri.

\section{Tartışma}

$\mathrm{Bu}$ çalışmanın sonucunda diz OA'lı hastalarda MPV düzeyleri ile hastalık radyolojik evresi arasında anlamlı istatistiksel bir fark bulunmadı. MPV seviyesi ile osteoartrit evreleri arasındaki ilişkinin değerlendirildiği birkaç çalışma mevcuttur. MPV düzeyi, sinoviti olan diz osteoartrit hastalarında hastalık evresi ile ters ilişkili bulunurken, kalça osteoartrit hastalarında hastalık evresi arttıkça yükseldiği saptanmıştır $(1,15,16)$. Sonuçların çelişkili olması, hastalık aktivitelerinin ve inflamasyon düzeylerinin farklı olmasına bağlanmıştır (16).

$\mathrm{Bu}$ çalışmada, MPV değeri ile hastaların fonksiyonel durumları, ESH, CRP arasında korelasyon saptanmadı. Sinoviti olan ve olmayan diz OA'lı hastalar ile kontrol grubunda inflamatuvar belirteçlerin MPV değerleri karşılaştırıldığı bir çalışmada, sinovitli hastalarda MPV ile inflamasyonun negatif ilişkili olduğu saptanmıştır (1). Kısacık ve ark. (4) yaptığı bir çalışmada ise romatoid artrit ve ankilozan spondilit hastalarında tedavi öncesi ve sonrası olmak üzere akut faz reaktanlarının MPV ile ilişkisi değerlendirilmiştir. MPV seviyesinin, romatoid artrit ve ankilozan spondilit hastalarında OA'ya göre daha düşük olduğu ve tedavi sonrası MPV değerinin yükseldiği gösterilmiştir (4). Bunun sonucunda MPV'nin romatoid artrit gibi hastalıklarda tedavinin takibinde kullanılabileceği düşünülmüştür (17). Çalışmamızda, MPV değerinin akut faz reaktanları ile anlamlı ilişkisinin bulunmaması, hasta grubumuzun inflamatuvar romatizmal hastalıklarda olduğu kadar yüksek ESH ve/veya CRP'ye sahip olmamasından kaynaklandığı yorumu yapılabilir.

Ayrıca, çalışmamızda, ESH, CRP değerleri ile platelet sayımı arasında korelasyon mevcuttu. Plateletlerin, 
kemik iliği aktivitesine bağlı olarak enfeksiyon ve inflamasyon sırasında sayıları değişebilir (18). İnflamatuvar barsak hastalarında yapılan bir çalışmada, hastalık aktivitesi sırasında platelet sayısının arttığı ve MPV değerlerinin azaldığı gözlenmiştir (10). Benzer olarak, erken dönemdeki akut romatizmal ateş hastalarında, kontrol grup ile kıyaslandığında belirgin olarak platelet sayısının yüksek ve MPV seviyesinin düşük olduğu saptanmıştır (19). Nötrofil sayımı gibi platelet sayımı da inflamatuvar yanıtı gösteren bir belirteçtir (1). Ayrıca, MPV değerinin inflamasyonda arttığını savunan çalışmalarla birlikte azaldığını gösteren çalışmalar da mevcuttur (1,4-7). Fakat genel görüş, MPV seviyesinin inflamasyon ile azaldığı ve MPV'nin hastalık aktivitesini gösteren bağımsız bir belirteç olarak kullanılabileceğidir.
Çalışmamızın bazı kısıtılıkları bulunmaktadır. İlk olarak çalışmaya dahil edilen hastalarımızda sinovit varlığı ultrasonografi, manyetik rezonans görüntüleme gibi objektif yöntemler ile değerlendirilememiştir. Radyolojik evreler ile MPV ilişkisinin de bakıldığı çalışmada, kontrol grubunun olmaması ve OA radyografik evrelerindeki hasta dağılımının eşit olmaması da diğer kısıtılıklarımızdır.

\section{Sonuç}

Sonuç olarak, diz OA'lı hastalarda klinik, laboratuvar ve radyografik değerlendirmeler ile MPV ilişkisi incelendi ve MPV seviyesinin; radyolojik evreden bağımsız olup, klinik durum, ESH ve CRP düzeyleri ile ilişkili olmadığı saptandı. Bununla birlikte, MPV'nin osteoartrit aktivitesindeki olası rolünün değerlendirilebilmesi için daha kapsamlı çalışmalara intiyaç vardır.

\section{Kaynaklar}

1. Balbaloglu O, Korkmaz M, Yolcu S, Karaaslan F, Beceren NG. Evaluation of mean platelet volume (MPV) levels in patients with synovitis associated with knee osteoarthritis. Platelets 2014;25(2):81-5.

2. Tezcan ME, Demir Ş, Sargın M, Aliustaoğlu M, Göker B. Sjögren's syndrome and mean platelet volume. Reumatismo 2015;67(1):33-4.

3. Soydinc S, Turkbeyler IH, Pehlivan Y, et al. AM. Mean platelet volume seems to be a valuable marker in patients with systemic sclerosis. Inflammation 2014;37(1):100-6.

4. Kisacik B, Tufan A, Kalyoncu U, Karadag O, Akdoğan A, Ozturk MA. Mean platelet volume (MPV) as an inflammatory marker in anklosing spondylitis and rheumatoid arthritis. Joint Bone Spine 2008;75(3):291-4.

5. Yazici S, Yazici M, Erer B, Calik Y, Ozhan H, Ataoğlu S. The platelet incides in patients with rheumatoid arthritis: Mean platelet volume reflects disease activity. Platelets 2010;21(2):122-5.

6. Gasparyan AY, Ayvazyan L, Mikhailidis DM, Kitas GD. Mean platelet volume: A link between thrombosis and inflammation? Curr Pharm Des 2011;17(1):47-58.

7. Karabulut M. To the Editor. Pediatr Cardiol 2015;36(6):1314-5.

8. Voudoukis E, Karmiris K, Koutroubakis IE. Multipotent role of platelets in inflammatory bowel diseases: A clinical approach. World J Gastroenterol 2014:20(12):3180-90.

9. Vakili M, Ziaee V, Moradinejad MH, Raeeskarami SR, Kompani F, Rahamooz T. Changes of platelet indices in juvenile idiopathic arthritis in acute phase and after two months treatment. Iran J Pediatr 2016;11;26(3):e5006.

10. Kapsoritakis AN, Koukourakis MI, Sfiridaki A, et al. Mean platelet volume: A useful marker of inflammatory bowel disease activity. Am J Gastroenterol 2001;96(3):776-81.

11. Balta S, Demirkol S, Cakar M, Celik T. Mean platelet volume as a surrogate marker of low-grade inflammation in osteoarthritis. Platelets 2014;25(8):643-4.

12. Basaran S, Guzel R, Seydaoglu G, Guler Uysal F. Validity, reliability and comparison of the WOMAC osteoarthritis index and lequesne algofunctional index in Turkish patients with hip or knee osteoarthritis. Clin Rheumatol 2010;29(7):749-56.

13. Bucland-Wright JC, Macfarlane DG, Williams SA, Ward RJ. Accuracy and precision of joint space width measurements in standart and macroradiographs of osteoarthritic knees. Ann Rheum Dis 1995;54(11):872-80.

14. Özdemir O. Medikal İstatistik. 1. Baskı. İstanbul: İstanbul Medikal Yayıncılık; 2006.

15. Akbal A, Gökmen F, Reşorlu H. The importance of synovitis diagnosis in osteoarthritis patients in the evaluation of mean platelet volume. Platelets 2015;26(3):277.

16. Taşoğlu Ö, Şahin A, Karataş G, et al. Blood mean platelet volume and platelet lymphocyte ratio as new predictors of hip osteoarthritis severity. Medicine 2017;96(6):6073.

17. Gasparyan AY, Sandoo A, Kalinoglou AS, Kitas GD. Mean platelet volume in patients with rheumatoid arthritis: The effect of anti-TNF-alfa therapy. Rheumatol Int 2010;30(8):1125-29.

18. Zareifar S, Farahmand Far MR, Golfeshan F, Cohan N. Changes in platelet count and mean platelet volume during infectious and inflammatory disease and their correlation with ESR and CRP. J Clin Lab Anal 2014;28(3):245-8.

19. Sert A, Aypar E, Odabas D. Mean platelet volume in acute rheumatic fever. Platelets 2013;24(5):378-82. 